\title{
Preciados feminismos. Una lectura de Preciado para la antropología filosófica
}

\author{
Mabel Campagnoli (2018) \\ Málaga, UMA Editorial
}

\section{Mónica D’Uva}

\author{
Lic. en Filosofía (UBA)
}

Ya desde su título el trabajo doctoral de Mabel Campagnoli señala lo que serán los desafíos más importantes abordados por el texto. En primer lugar, la puesta en valor de todos los recorridos del quehacer feminista tanto de sus luchas como de sus derivas teóricas. Desde esta doble inserción serán (a)preciados los feminismos. El siguiente desafío, una lectura de "Preciado", a secas, sin nombre propio alguno, ofrece, no solo y alegremente, un juego de sentidos sino que instala un primer indicio de la complejidad del análisis, el de un pensamiento desanclado de una identidad fija y reinscrito en una subjetividad puesta en entredicho. Así, Campagnoli atiende al otro gran desafío de su propuesta, la obligación de dar cuenta de la encarnadura de la tarea filosófica, desmontando el androcentrismo presente en la tradición de la antropología filosófica al promover una indagación de la experiencia humana que se sitúa en las antípodas de un sujeto humano trascendental.

Colocado este primer marco se define la tarea a realizar: la clarificación teórico-política de los textos de Preciado en el período que se extiende desde 2000 hasta 2010, abarcando sus obras Manifiesto contrasexual, Testo Yonqui y Pornotopía. La intención es identificar y resaltar el aporte conceptual de Preciado al feminismo y a la filosofía política. La compleja labor es llevada a cabo por Campagnoli mediante la elaboración de una perspectiva genealógica múltiple para dar cuenta de distintos acoplamientos de saberes: erudición y militancia en el desarrollo de las condiciones de producción de los textos; biopolítica y género en la reconstrucción del contenido de los mismos.

En este sentido, el análisis muestra los linajes presentes en la concepción de la biopolítica - heredera de la recepción italiana de Michel Foucault, a través de las voces de Agamben, Negri, Espósito y Lazzarato, entre otros-y del concepto de género, deudor de las ciencias médico-psicológicas, las ciencias sociales y los feminismos.

De esta manera, podemos valorar las aportaciones del filósofo a cada uno de estos ámbitos, la biopolítica y el género. Sin ánimo de sintetizar, tarea imposible, destacamos una lectura que muestra la contribución de Preciado a una biopolítica afirmativa a partir del lugar que le otorga a la noción de potentia gaudendi en tanto "motor de las formaciones vitales, cualquiera sea la figura que adquieran en la trama de la existencia” (p. 271). En este sentido, la noción está a la base de la biopolítica, que así deviene sexo-política, y permite articular las dimensiones económica y subjetiva del capitalismo contemporáneo.

Asimismo, la consideración prostética del género resaltará la materialidad del cuerpo y sus producciones, al poner el énfasis en la inscripción somática de los procedimientos del dispositivo de género, mostrando el carácter encarnado de la performatividad ( $p$. 333). En este análisis cobra relevancia la funcionalidad de la dicotomía jerárquica de géneros para el capitalismo actual a partir de sus particulares procedimientos de naturalización de las identidades.

La novedad de una perspectiva positiva de la biopolítica leída ahora como sexo-política o más precisamente como fármaco-porno-política, permite acercarnos a la comprensión de prácticas contrasexuales que modifican las "tecnologías del yo" hacia "tecnologías del un* mism*". De esta manera, se materializa en el lenguaje una voz no dicotómica como puesta en juego de una práctica de resistencia.

Así la lectura ofrecida permite inferir la autoridad filosófica de una voz trans. Al hacerlo, reconoce la legitimidad de un sujeto político y filosófico transfeminista. Cuestión que se resalta además en las conclusiones, cuando muestran la actualidad del dispositivo conceptual reconstruido: "continúa penalizada la práctica del aborto y está vigente la perspectiva abolicionista en materia de prostitución, que desconoce las voces de algunos grupos de 
prostitutas. Consideramos que una manera de abrir sentidos en los debates sociales y de las movilizaciones feministas para estas problemáticas reside en asumir la base sexual de ambas cuestiones; esto es, pensarlas en perspectiva sexo-política" (p. 448).

A lo largo de seis capítulos y casi quinientas páginas, la riqueza y originalidad del pensamiento de Preciado se nos abre con claridad metodológica y epistemológica. La lectura ofrecida en el libro atisba además, nuevamente a partir de la noción de potentia gaudendi, ampliar el alcance de la biopolítica afirmativa en un sentido posthumanista. De este modo, se señalan posibles líneas de diálogo con posturas afines en Donna Haraway, Rosi Braidotti, Suely Rolnik.

Finalmente, nos interesa observar la factura del libro en tanto objeto, cuya portada se basa en el óleo Mujer-Hombre, de la artista plástica argentina Ángeles Herrera. Ese estímulo visual también ofrece una apertura a los efectos de sentido de las claves conceptuales. 